\title{
A Methodology to Investigate Powered Two-Wheeler Rider's Comfort over Road Sections with Skew Superelevation
}

\author{
PANAGIOTIS LEMONAKIS, GEORGE KALIABETSOS, NIKOLAOS MOISIADIS, \\ NIKOLAOS ELIOU \\ Department of Civil Engineering, Section of Transportation, University of Thessaly, \\ Pedion Areos, 38334 Volos, GREECE
}

\begin{abstract}
The proper surface water drainage not only affects vehicle movement dynamics but also increases the likelihood of an accident since inadequate drainage is associated with potential hydroplaning and splash and spray driving conditions. Nine solutions have been proposed to address hydroplaning in sections with inadequate drainage e.g. augmented superelevation and longitudinal slope, reduction of runoff length, and skew superelevation. The latter has been extensively implemented in highways recently, enhancing the safety level in the applied road segments regarding the effective drainage of the rainwater. However, the concept of the skew superelevation has raised concerns regarding the level of driver's comfort when traveling over skew superelevation sections particularly with high speeds. These concerns were alleviated through the concept of the round-up skew superelevation which reduces both the lateral and the vertical acceleration imposed on the drivers and hence, improves comfort and traffic safety.

The present study investigates the behaviour of power two-wheeler riders since they are susceptible to any changes on the pavement surface and therefore a comparison between the traditional superelevation practice and the skew superelevation concept is of paramount importance. The methodology is based on the utilization of sophisticated software to design the model of the road for several values of longitudinal slopes. Based on the values of the slopes and the use of mathematical equations, the accelerations imposed on the wheel of the motorcycle were calculated. Since the final aim of the study is the influence of the skew superelevation to the rider, it was deemed necessary to convey the calculated accelerations from the wheel to the rider. That was accomplished by implementing the quarter car suspension model adjusted to the features of two-wheeler vehicles. Finally, the accelerations derived from this process evaluated according to specific thresholds based on the literature which correspond to certain levels of comfort.

The most important conclusion drawn is that the comfort of the riders is not dependent to a great extent on the form of the road gradient because the vertical acceleration imposed on the riders took similar values regardless of the value of the longitudinal slope.
\end{abstract}

Key-Words: Acceleration, Comfort, Motorcycle, Safety, Skew Superelevation, Quarter Car Suspension Model, Motorcycle Ride Analysis,

Received: April 9, 2021. Revised: October 13, 2021. Accepted: November 1, 2021. Published: November 22, 2021.

\section{Introduction}

The sufficient drainage of the rainwater from the road surface is a crucial parameter that every road designer should pay attention to. Improper rainwater runoff might tremendously affect a vehicle's movement dynamics and lead to collisions and crashes [1]. The traditional practice of rotating the axis of the road at the beginning of the transition curve results in areas of small compound slope which magnitude depends on the length of the transition curve and the value of the longitudinal slope. Therefore, the vehicles entering a curve on rainy days might travel under hydroplaning or splash and spray conditions which constitute major factors of vehicular accidents $[2,3]$.
All cross-sections where the cross slope is less than $0.5 \%$ are sections where problems relevant to the improper drainage might emerge. Many alternatives have been proposed to mitigate this phenomenon one of which is the implementation of the skew superelevation at a certain segment that precedes the horizontal curve.

Various research studies have been carried out aiming to investigate driving comfort through the evaluation of the lateral and the vertical accelerations sustained by the road users and the vehicles. These studies focused on the influence of the skew superelevation to passenger cars, buses, and trucks and the drivers themselves, traveling at a certain range of speeds either below or above the design speed. The outcome of these investigations which was based on the use of simulations revealed 
that the imposed accelerations did not exceed the statutory thresholds even when the traveling speed was significantly greater than the design speed. Nevertheless, the effect of the skew superelevation to other vehicle types for instance motorcycles has not been investigated so far. The present research study aims to bridge this gap by investigating the impact of skew superelevation on the motorcycle rider's comfort.

The present research study investigates the comfort that motorcycle riders experience as they travel over such sections and identify combinations of longitudinal and superelevation rates that provide the maximum possible comfort to motorcycle riders. That is accomplished by examining the developed accelerations imposed on the body of the motorcycles under different values of longitudinal slope and skew superelevation rates. More specifically, five different values of longitudinal slopes $(-0.5 \%,-1.0 \%, 0.0 \%,+0.5 \%$ and $+1.0 \%)$ and two different values of skew superelevation rates i.e. the widespread transition from $-2.5 \%$ to +2.5 (Fig. 1) and an alternative one from $-1.0 \%$ to $+1.0 \%$, have been combined in order to calculate the developed vertical accelerations.

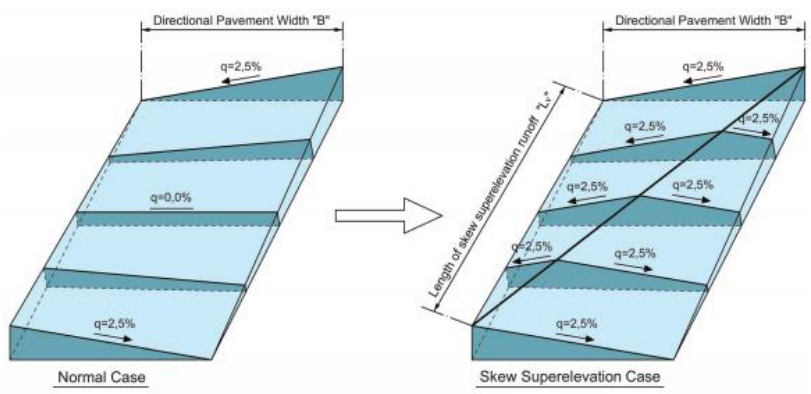

Fig. 1: Normal and Skew Superelevation case [4]

For that purpose, sophisticated road design software has been used [5], to design the road section models and produce the profile of the median line of the travel lane, where the powered two-wheeler (PTW) vehicles are assumed to travel. These profiles were then properly processed to calculate the resulting vertical accelerations. The latter evaluated according to the human exposure limits determined by the European Commission and consequently, useful conclusions were drawn regarding the effect of skew superelevation rates in conjunction with various values of longitudinal slope to motorcycle riders' comfort.

\section{Road Models}

The road model on which the investigation carried out concerns an existing motorway that was recently constructed based on the concept of the skew superelevation, located in Central Greece. Each traffic direction consists of two traffic and one emergency lane whereas the carriageways are separated with concrete barriers. The attributes and particularly the widths of the various road elements of the case study road segment are presented in Fig. 2.

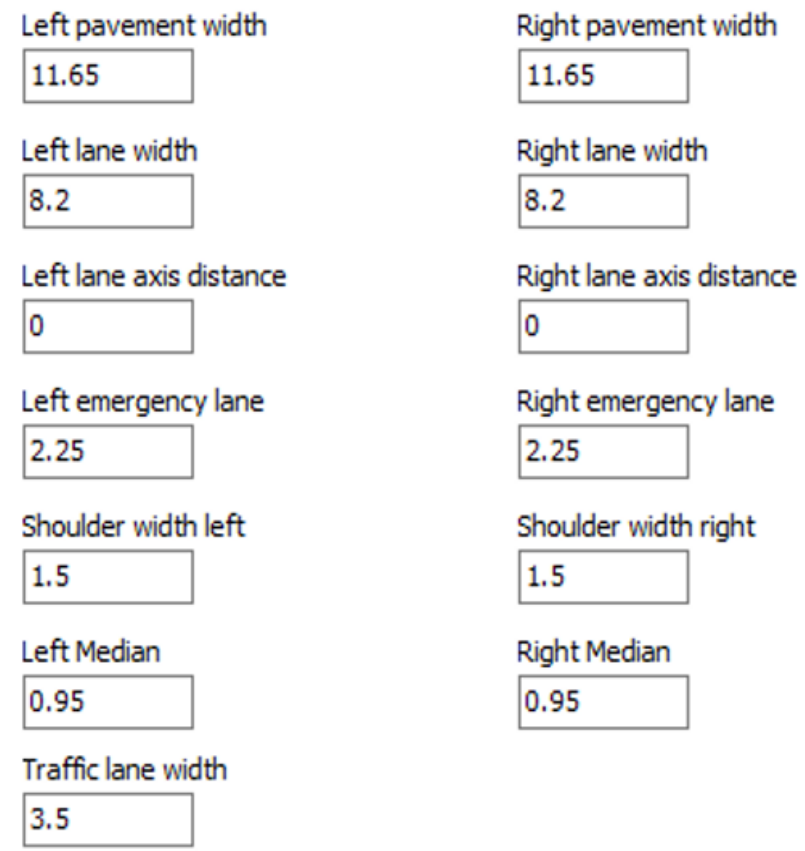

Fig. 2: Widths of the case study road segment

The road models that were used to calculate the profile of the median line of the travel lane were divided into three sections, according to the applied superelevation; the first and the third section of 10 $\mathrm{m}$ length each where the superelevation rate is fixed and the second one of $50 \mathrm{~m}$ length where the skew superelevation is either $2.5 \%$ or $1.0 \%$. Fig. 3 illustrates the longitudinal profile for the aforementioned slopes i.e., $-1.0 \%,-0.5 \%, 0.0 \%$, $+0.5 \%$ and $+1.0 \%$. The red, cyan, light blue, and green-blue lines represent the profile of the longitudinal slope, the skew superelevation $2.5 \%$, the skew superelevation $1.0 \%$, and the profile without the implementation of the skew superelevation respectively. Lastly, the dots that lie on the lines represent the individual cross-sections. In the figure are also marked the cross-sections of the turning points of each line. On all of the profile drawings in Fig. 3 the cross sections 20, 50, 70, 90 and 120 are marked for further investigation and particularly to identify whether in these cross sections the longitudinal slope changes value or not. 
Apparently, the vertical acceleration imposed on the motorcycle is zero throughout the cross-sections with constant longitudinal slope whereas it is not zero only at the turning points of the profile lines and therefore the investigation is narrowed to those cross-sections where the longitudinal slope change value. According to our analysis, the turning points are identified in two cross-sections when the skew superelevation of $2.5 \%$ is applied and in five crosssections when the skew superelevation of $1.0 \%$ is applied.

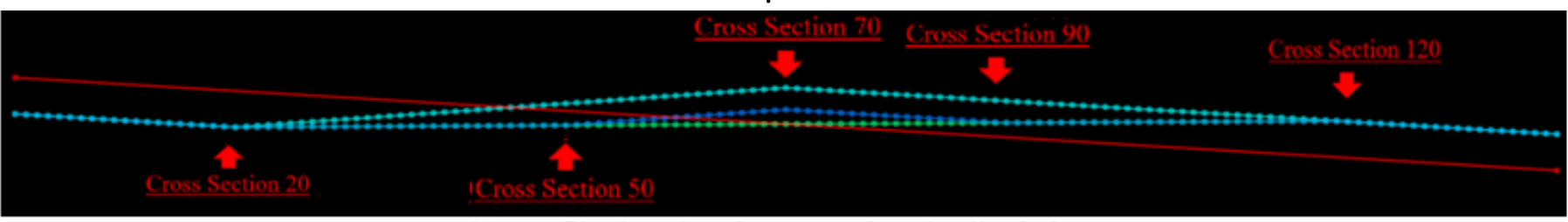

(a) Profile drawing for $-1.0 \%$ longitudinal slope

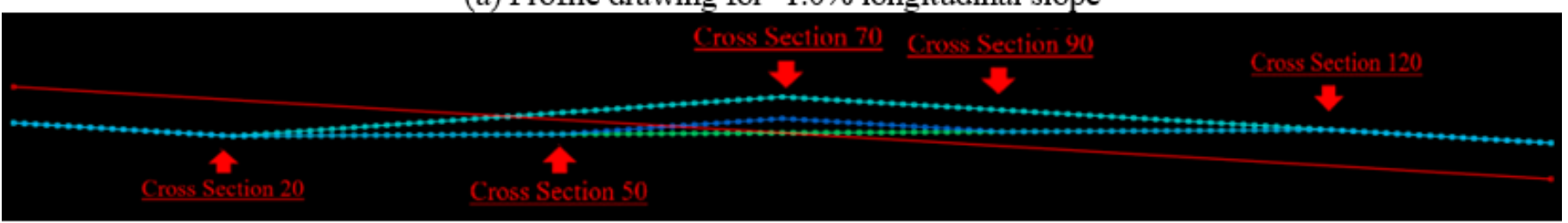

(b) Profile drawing for $-0.5 \%$ longitudinal slope

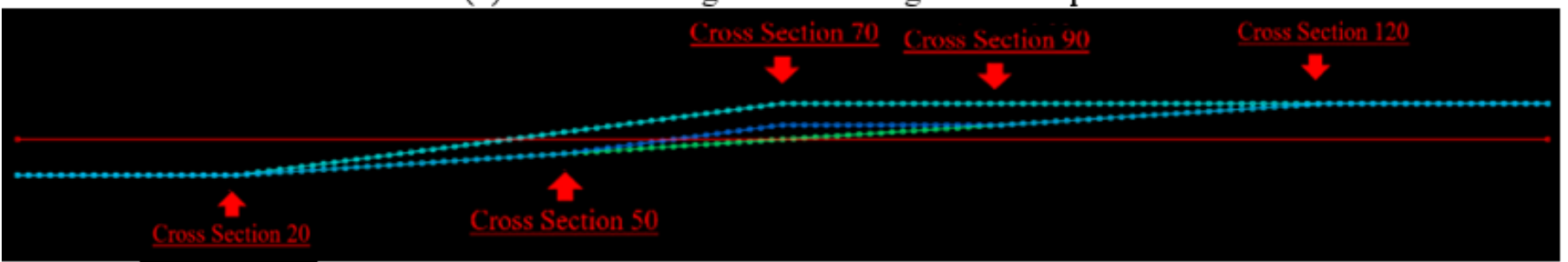

(c) Profile drawing for $0 \%$ longitudinal slope

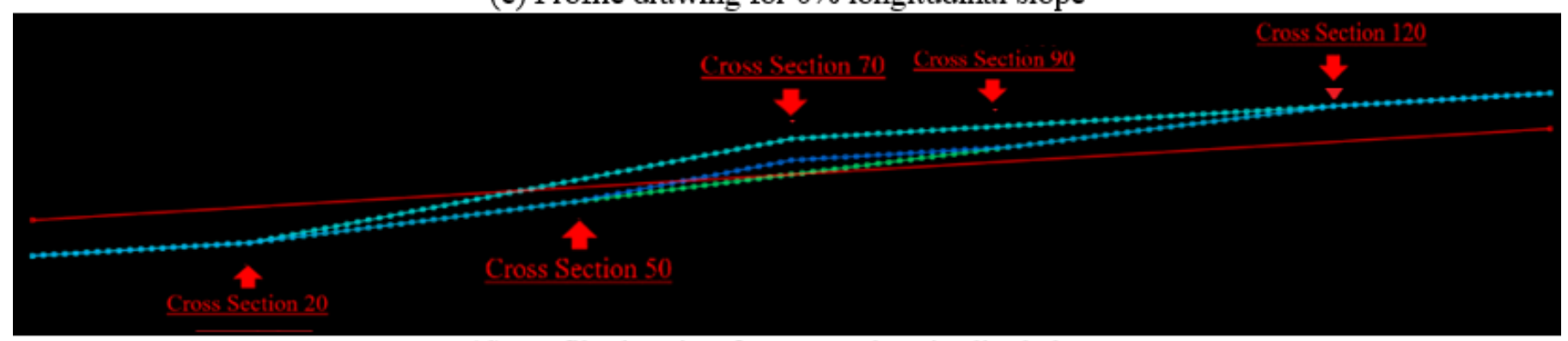

(d) Profile drawing for $+0.5 \%$ longitudinal slope

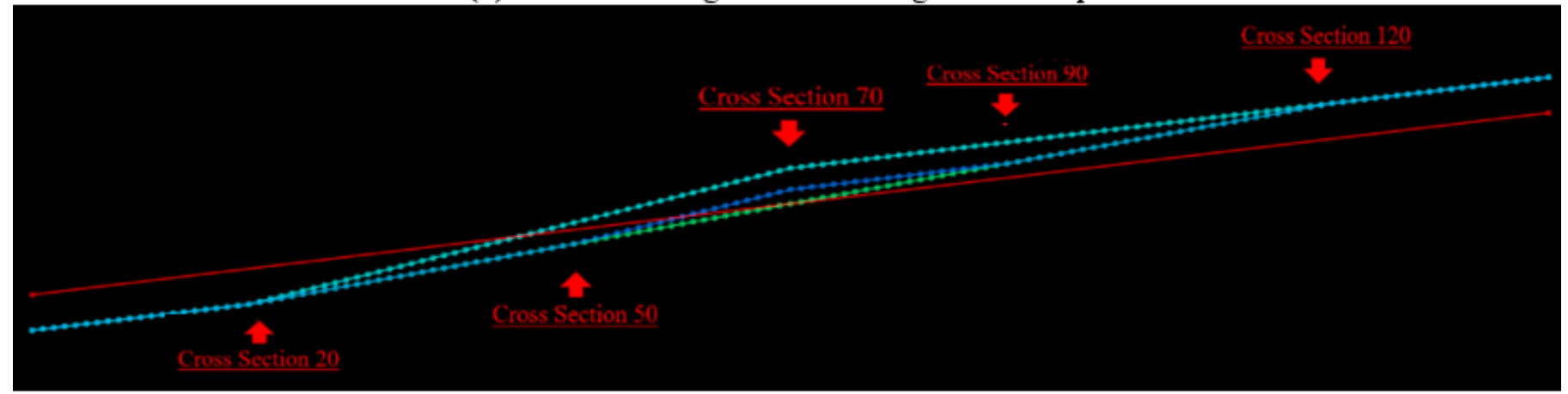

(e) Profile drawing for $1.0 \%$ longitudinal slope

Fig. 3: Profile drawings for $-1.0 \%,-0.5 \%, 0 \%,+0.5 \%$ and $1.0 \%$ longitudinal slopes

\section{Calculation of Vertical Acceleration}

The next step of the analysis is the calculation of the vertical acceleration at the cross-sections where the longitudinal slope changes. A vertical acceleration $a$ is imposed on a vehicle traversing a vertical curve (slope change from $p$ to $q$ ) with constant wheel speed due to the 
change of the vertical component of the speed. This acceleration is called centripetal acceleration and it is given by the equation (1):

$$
\alpha=\frac{v^{2}}{r}
$$

where $r$ is the radius of the circular curve that approximates the vertical parabola curve, $v$ is the speed of the vehicle and $1 / r$ is the curvature $k$. The general equation for the curvature of a curve $y=f(x)$ is given by equation (2):

$$
k= \pm \frac{\left(\frac{d^{2} y}{d x^{2}}\right)}{\left\{1+\left(\frac{d y}{d x}\right)^{2}\right\}^{\frac{3}{2}}}
$$

At vertical curves, the fraction $d y / d x$ corresponds to the gradient which is usually small whereas the quantity $(d y / d x)^{2}$ is too small (compared to 1) and can be omitted. Therefore, the curvature $k$ is given approximately by equation (3):

$$
k \approx \frac{d^{2} y}{d x^{2}}
$$

The basic requirement of the vertical curves used in road design is that the rate of change of gradient against the horizontal distance must be constant. This requirement can be expressed in two ways:

Given that the gradient can be the derivative $d y / d x$ then the rate of change of the gradient is the second derivative and is given by equation (4):

$$
\frac{d^{2} y}{d x^{2}}=k
$$

Given also that the rate of change of the gradient is a constant $k$ then it is also equal to the total change of the gradient $A$ divided by the length $L$ (Fig. 4) and hence it is also given by the equation (5):

$$
\frac{q-p}{L}=\frac{A}{L}=K
$$

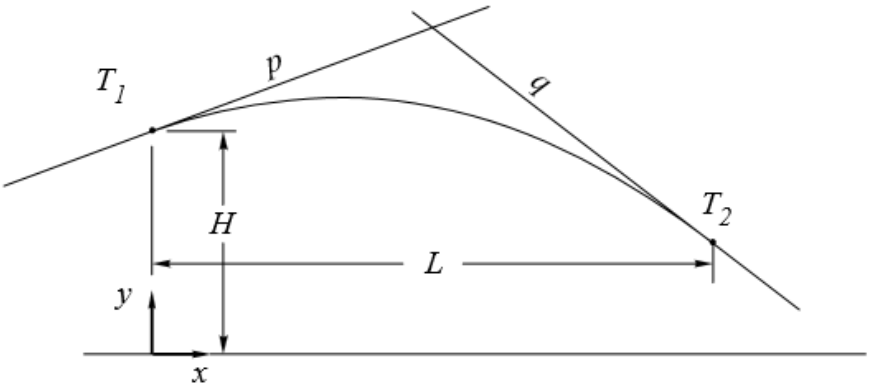

Fig. 4: Geometric characteristics of the vertical curve

For the parabola vertical curve, the quantity $d^{2} y / d x^{2}$ (the rate of change of the gradient) is a constant $K$ and hence, equation (3) in conjunction with equations (4) and (5) can be written as follows:

$$
\frac{d^{2} y}{d x^{2}}=K=\frac{q-p}{L}
$$

Lastly, by combining equations [1] and [6] the vertical acceleration imposed on a vehicle that travels on a road segment of different gradients is given by equation [7]:

$$
a=\frac{(q-p) v^{2}}{L}
$$

As stated, the road models that were produced for the needs of the present research study have a constant longitudinal slope and therefore equation (7) is valid only under the assumption that the calculated acceleration concerns the wheel and not the vehicle. Another assumption is that the motorcycle is traveling with a fixed value of $120 \mathrm{~km} / \mathrm{h}$ or $33.33 \mathrm{~m} / \mathrm{s}$. The last assumption is that the edge of the skew superelevation is smoothed in a width of $0.5 \mathrm{~m}$ [6] a widespread practice among the road sections where the skew superelevation technique has been applied so far and hence with the speed of $33.33 \mathrm{~m} / \mathrm{s}$ the developed vertical acceleration is exerted to the body of the rider for $0.015 \mathrm{~s}$.

The implementation of equation (7) in conjunction with the gradients that derive from the longitudinal profile of the median line of the travel lane as presented in Fig. 3 in every crosssection of gradient change, results in Table 1 . The table is divided into the upper part that corresponds to the skew superelevation value of 
$2.5 \%$ and the lower part which corresponds to the skew superelevation of $1.0 \%$. The first column of Table 1 includes the number of the cross-section where the vertical acceleration develops, the next two columns the slopes before and after the change of gradient according to the longitudinal profile for every combination of longitudinal slope and skew superelevation rate, and the last column the calculated vertical acceleration according to equation [7].
As mentioned before the vertical accelerations included in Table 1 are not the ones that are imposed to the rider of the motorcycle but those that are sustained by the wheel. Therefore, these accelerations should be properly conveyed to the rider to evaluate whether they cause discomfort or not, based on the statutory thresholds. This process is achieved through the implementation of the quarter car suspension model, properly adjusted to comply with the 2-wheelers characteristics.

Table 1. Vertical accelerations

\begin{tabular}{|c|c|c|c|c|c|c|c|c|c|c|c|c|c|c|}
\hline \multicolumn{15}{|c|}{ Skew Superelevation $2.5 \%$} \\
\hline \multirow[t]{3}{*}{$\begin{array}{l}\text { Cross } \\
\text { Section }\end{array}$} & \multicolumn{3}{|c|}{$\begin{array}{c}\text { Road Axis Gradient } \\
-1 \%\end{array}$} & \multicolumn{3}{|c|}{$\begin{array}{c}\text { Road Axis Gradient } \\
-0.5 \%\end{array}$} & \multicolumn{3}{|c|}{$\begin{array}{c}\text { Road Axis Gradient } \\
0 \%\end{array}$} & \multicolumn{3}{|c|}{$\begin{array}{c}\text { Road Axis Gradient } \\
+0.5 \%\end{array}$} & \multicolumn{2}{|c|}{$\begin{array}{c}\text { Road Axis Gradient } \\
+1 \%\end{array}$} \\
\hline & \multicolumn{2}{|c|}{ Slope $(\%)$} & \multirow{2}{*}{$\begin{array}{c}a \\
\left(\mathrm{~m} / \mathrm{s}^{2}\right) \\
\end{array}$} & \multicolumn{2}{|c|}{ Slope $(\%)$} & \multirow{2}{*}{$\begin{array}{c}a \\
\left(\mathrm{~m} / \mathrm{s}^{2}\right)\end{array}$} & \multicolumn{2}{|c|}{ Slope $(\%)$} & \multirow{2}{*}{$\begin{array}{c}a \\
\left(\mathrm{~m} / \mathrm{s}^{2}\right)\end{array}$} & \multicolumn{2}{|c|}{ Slope (\%) } & \multirow{2}{*}{$\begin{array}{c}a \\
\left(\mathrm{~m} / \mathrm{s}^{2}\right) \\
\end{array}$} & Slope $(\%)$ & \multirow{2}{*}{$\begin{array}{c}a \\
\left(\mathrm{~m} / \mathrm{s}^{2}\right)\end{array}$} \\
\hline & $\mathrm{p}$ & $q$ & & $\mathrm{p}$ & $\mathrm{q}$ & & $\mathrm{p}$ & $q$ & & $\mathrm{p}$ & $q$ & & $q$ & \\
\hline 20 & -0.010 & 0.001 & 24.44 & -0.005 & 0.006 & 24.44 & 0.000 & 0.011 & 24.44 & 0.005 & 0.016 & 24.44 & $\begin{array}{ll}0.010 & 0.021\end{array}$ & 24.44 \\
\hline 70 & 0.001 & -0.010 & -24.44 & 0.006 & -0.005 & -24.44 & 0.011 & 0.000 & -24.44 & 0.016 & 0.005 & -24.44 & $0.021 \quad 0.010$ & -24.44 \\
\hline
\end{tabular}

\section{Skew Superelevation 1.0\%}

\begin{tabular}{|c|c|c|c|c|c|c|c|c|c|c|c|c|c|c|c|}
\hline \multirow[t]{3}{*}{$\begin{array}{l}\text { Cross } \\
\text { Section }\end{array}$} & \multicolumn{3}{|c|}{$\begin{array}{c}\text { Road Axis Gradient } \\
-1 \%\end{array}$} & \multicolumn{3}{|c|}{$\begin{array}{c}\text { Road Axis Gradient } \\
-0.5 \% \\
\end{array}$} & \multicolumn{3}{|c|}{$\begin{array}{c}\text { Road Axis Gradient } \\
0 \% \\
\end{array}$} & \multicolumn{3}{|c|}{$\begin{array}{c}\text { Road Axis Gradient } \\
+0.5 \%\end{array}$} & \multicolumn{3}{|c|}{$\begin{array}{c}\text { Road Axis Gradient } \\
+1 \%\end{array}$} \\
\hline & \multicolumn{2}{|c|}{ Slope (\%) } & \multirow{2}{*}{$\begin{array}{c}a \\
\left(\mathrm{~m} / \mathrm{s}^{2}\right) \\
\end{array}$} & \multicolumn{2}{|c|}{ Slope $(\%)$} & \multirow{2}{*}{$\begin{array}{c}a \\
\left(\mathrm{~m} / \mathrm{s}^{2}\right) \\
\end{array}$} & \multicolumn{2}{|c|}{ Slope (\%) } & \multirow{2}{*}{$\begin{array}{c}a \\
\left(\mathrm{~m} / \mathrm{s}^{2}\right) \\
\end{array}$} & \multicolumn{2}{|c|}{ Slope (\%) } & \multirow{2}{*}{$a\left(\mathrm{~m} / \mathrm{s}^{2}\right)$} & \multicolumn{2}{|c|}{ Slope (\%) } & \multirow{2}{*}{$\left(\mathrm{m} / \mathrm{s}^{2}\right)$} \\
\hline & $\mathrm{p}$ & q & & $\mathrm{p}$ & q & & $\mathrm{p}$ & q & & $\mathrm{p}$ & $q$ & & $\mathrm{p}$ & $q$ & \\
\hline 20 & .010 & .005 & 11.11 & .005 & 0.00 & 22.22 & 0.000 & 0.0 & 13.33 & 100 & & & & & \\
\hline 50 & .005 & 0.00 & & & 0.0 & & & & & & & & & & \\
\hline 7 & 0 & 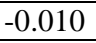 & & & 5 & 24. & & 0. & & & & & & & \\
\hline 9 & & 0.00 & & & & & & & & & & & & & \\
\hline 20 & .005 & -0.01 & .11 & 0.005 & 0.005 & 22.22 & .006 & 0.000 & 13.33 & 0.010 & 0.005 & -11.11 & 0.015 & 0.01 & -11.11 \\
\hline
\end{tabular}

\section{Quarter Car Suspension Model}

The parameters of a random motorcycle are presented in this chapter together with the assumptions for the motorcycle suspension of the front wheel both necessary for the implementation of the quarter car suspension model (Fig. 5). Note that the process can also be applicable for the rear wheel if the relevant data are used and that only the vertical degree of freedom is considered. The net result is the calculation of the acceleration imposed to the framework of the motorcycle and hence to the rider himself. Apparently, the rest of the assumptions to implement the quarter car suspension model are met e.g. the tire is considered as a linear spring without damping, the rotation of both the wheel and the chassis is neglected, the spring and the damper behave linear, constant contact between the tire and the pavement is assured and lastly the effect of friction is also neglected [7].

The equations that describe the motion of the sprung [8] and the unsprung [9] masses are the following:

$$
m_{s} \ddot{z}_{s}+k_{s}\left(z_{s}-z_{u}\right)+c_{s}\left(\dot{z}_{s}-\dot{z}_{u}\right)=0
$$

$$
m_{u} \ddot{z}_{u}+k_{s}\left(z_{u}-z_{s}\right)+c_{s}\left(\dot{z}_{u}-\dot{z}_{s}\right)+k_{t}\left(z_{u}-z_{r}\right)=0
$$

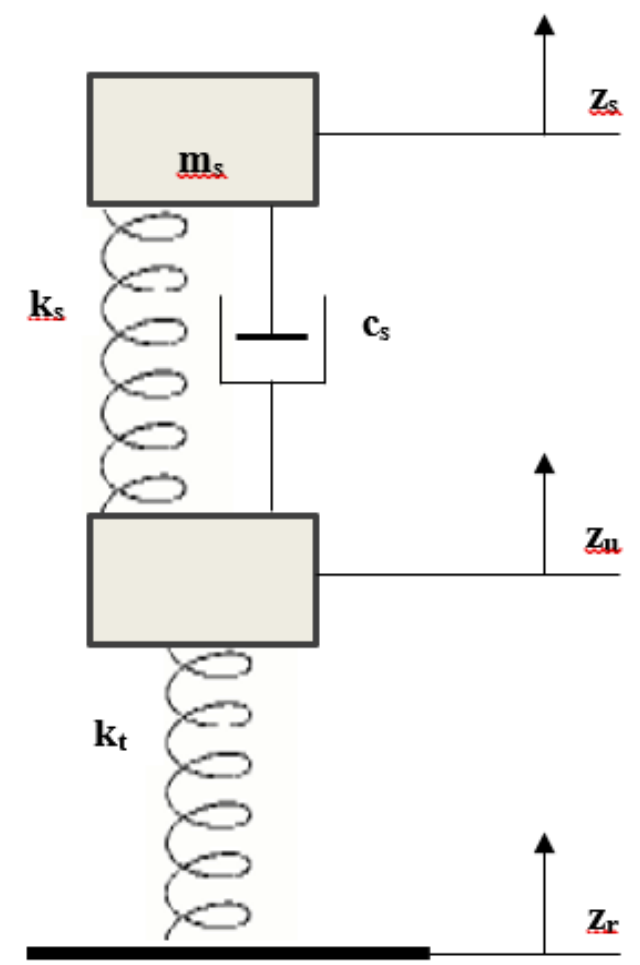

Fig. 5: 2-Degree of freedom quarter car suspension model 
where:

$m_{s} \quad$ mass of half of the motorcycle body (sprung mass) (kg)

$m_{u} \quad$ mass of the wheel and suspension (unsprung mass) (kg)

$z_{s} \quad$ sprung mass displacement (m)

$z_{u} \quad$ unsprung mass displacement (m)

$z_{r} \quad$ ground displacement $(\mathrm{m})$

$c_{t} \quad$ damping constant of the wheel and tire $(\mathrm{N} / \mathrm{m})$

$k_{t} \quad$ spring constant (stiffness) of the wheel and tire $(\mathrm{N} / \mathrm{m})$

$c_{s} \quad$ damping constant of the suspension system $(\mathrm{N} / \mathrm{m})$

$k_{s} \quad$ spring constant (stiffness) of the suspension system $(\mathrm{N} / \mathrm{m})$

$\dot{z}_{s} \quad$ sprung mass velocity $(\mathrm{km} / \mathrm{h})$

$\dot{z}_{u} \quad$ unsprung mass velocity $(\mathrm{km} / \mathrm{h})$

$\ddot{z}_{S} \quad$ sprung mass acceleration $\left(\mathrm{m} / \mathrm{s}^{2}\right)$

$\ddot{z}_{u}$ unsprung mass acceleration $\left(\mathrm{m} / \mathrm{s}^{2}\right)$

Table 2. Vehicle Parameters and Assumption Definitions

\begin{tabular}{llc}
\hline & Coefficient & Value \\
\hline $\mathrm{m}_{\mathrm{u}}$ & $(\mathrm{kg})$ & 18 \\
\hline $\mathrm{m}_{\mathrm{s}}$ & $(\mathrm{kg})$ & 137 \\
\hline $\mathrm{k}_{\mathrm{s}}$ & $(\mathrm{N} / \mathrm{m})$ & 79,314 \\
\hline $\mathrm{c}_{\mathrm{s}}$ & $(\mathrm{Ns} / \mathrm{m})$ & 3,000 \\
\hline $\mathrm{k}_{\mathrm{t}}$ & $(\mathrm{N} / \mathrm{m})$ & 400,000 \\
\hline$\dot{\mathrm{z}}_{\mathrm{s}}-\dot{\mathrm{z}}_{\mathrm{u}}$ & $(\mathrm{m} / \mathrm{s})$ & 0.04 \\
\hline \hline & $z_{u}$ & 3 \\
& $z_{s}$ & $\frac{3}{1}$ \\
\hline & $\mathrm{z}_{\mathrm{r}}$ & 0 \\
\hline
\end{tabular}

The implementation of equations [8] and [9] requires the definition of several assumptions especially the ones for the velocity and the acceleration of the sprung and unsprung masses. Those are presented in Table 2 which also includes the coefficients for a random vehicle i.e., Kawasaki ZX10R. The reason behind this selection is that its specifications are easily accessible through the internet [8]. Note also that the sprung mass encompasses the proportional to the frontal tire weight of one passenger.

Considering the values of Table 2 along with the accelerations that were calculated in Chapter 3 and presented in Table 1 the calculation of the accelerations imposed to the rider i.e., the corresponding value of $\ddot{z}_{s}$, according to the various combinations of skew superelevation and longitudinal slope is feasible. The results of this process are presented in Table 3 which derives from Table 2 in conjunction with Table 1 without considering the duplicate values of unsprung acceleration.

Table 3. Calculation of Sprung Acceleration

\begin{tabular}{cc}
$\begin{array}{c}\text { Unsprung acceleration } \\
\ddot{z}_{u}\left(\mathrm{~m} / \mathrm{s}^{2}\right)\end{array}$ & $\begin{array}{c}\text { Sprung acceleration } \\
\ddot{z}_{s}\left(\mathrm{~m} / \mathrm{s}^{2}\right)\end{array}$ \\
\hline 24.44 & -1.15 \\
\hline-24.44 & -0.40 \\
\hline 11.11 & -0.94 \\
\hline-11.11 & -0.60 \\
\hline 13.33 & -0.98 \\
\hline
\end{tabular}

\section{Evaluation of Riders' Comfort}

The evaluation of rider's comfort performed by comparing the accelerations exerted to the rider i.e. values of sprung acceleration $\ddot{z}_{S}$, as they were presented in Table 3 with the vertical acceleration threshold of $1.2 \mathrm{~m} / \mathrm{s}^{2}$ adopted by the European Commission, as discussed by Apostoleris et al [4]. Note that the value of $1.2 \mathrm{~m} / \mathrm{s}^{2}$ is associated with the comfort level of the driver and is valid only for the vertical values of the acceleration. From the comparison, it can be inferred that none of the calculated vertical acceleration values exceed the threshold of the $1.2 \mathrm{~m} / \mathrm{s}^{2}$ and hence the combinations of skew superelevation and gradient rates examined in the present research study do not cause discomfort to the riders of Kawasaki ZX10R traveling over road sections with skew superelevation with a speed of $120 \mathrm{~km} / \mathrm{h}$.

However, for different combinations of skew superelevation and gradient values or higher speeds, the aforementioned threshold might be violated. For instance, in road sections where the skew superelevation is $2.5 \%$ if the travel speed increases from $120 \mathrm{~km} / \mathrm{h}$ to $130 \mathrm{~km} / \mathrm{h}$ the developed acceleration to the chassis of the motorcycle and consequently to the rider himself is greater than the limit of $1.2 \mathrm{~m} / \mathrm{s}^{2}$. Obviously, that is valid only if the test vehicle and the rest of the road geometric characteristics remain unchanged.

Nevertheless, in practice, the edge of the skew superelevation is rounded in a width of up to $5.0 \mathrm{~m}$ [4] and hence in this case according to equation (7) the exerted vertical superelevation is reduced by 10 times compared to the width that was assumed in the present case study of $0.5 \mathrm{~m}$. Therefore, the designer can choose the round length of the skew superelevation edge in a way that ensures no breach of the vertical acceleration threshold, for a given design or operating speed. 


\section{Conclusions and Recommendations for Further Research}

In the present research study, a methodology to evaluate the comfort experienced by motorcycle riders traveling over road sections where the skew superelevation has been applied is introduced. Furthermore, the proposed methodology is implemented for a given motorcycle in road sections of five different values of longitudinal slope either for $2.5 \%$ or $1.0 \%$ values of skew superelevation. The latter case results in five cross-sections and the former in two cross-sections where the slope changes value and consequently vertical acceleration emerges.

Although the greater the value of the skew superelevation the better the drainage of the rainwater from the road pavement, the developed vertical acceleration is also increased and consequently, the vertical acceleration threshold for a given width of edge rounding, travel speed, and vehicle features might be breached. The maximum vertical acceleration is developed in two crosssections of each combination between $2.5 \%$ skew superelevation rate and road gradient. Aiming at mitigating the impact of high values of skew superelevation to the comfort experienced by road users the road designers can select smoother edges i.e. wider transition zones of skew superelevation slope changes.

On the other hand, according to Fig. 3 the smaller value of skew superelevation rate i.e. $+1 \%$ results in smoother transitions over the skew road section and hence, a higher level of comfort since the developed vertical accelerations in the four out of the five cross-sections are less than the ones developed in the case of $2.5 \%$ skew superelevation rate. Moreover, the application of $1 \%$ skew superelevation rate requires less total and partial height and less total space (see Fig. 3). However, future research is recommended to investigate the effect of skew superelevation values on the drainage of the rainwater from the pavement, other than the widespread value of $2.5 \%$. Lastly, the application of $1 \%$ skew superelevation, results in the development of the maximum acceleration only in one crosssection and consequently, the driver perceives better comfort.

The calculated vertical accelerations were then properly conveyed to the chassis of the motorcycle and consequently to the rider himself by implementing the quarter car suspension model adjusted to the features of a random motorcycle and particularly a Kawasaki ZX10R because its parameters e.g. weight of the sprung and unsprung mass, spring and damping constant, were freely available on the internet. The process concluded that the threshold of the vertical acceleration exerted to the rider for the investigated case studies of skew superelevation rates and road gradient, has never been breached. Apparently, that is only valid for the given vehicle, however, the proposed methodology can be implemented in any kind of two- or fourwheel vehicle if the necessary technical features are known.

\section{References:}

[1] P. Lemonakis, T. Alimonakis, G. Kaliabetsos and N. Eliou, "Identifying Areas on the Pavement Where Rain Water Runoff Affect Motorcycle Behavior," in 22nd International Conference on Highway Design and Construction, Tokyo, 2020.

[2] J. Granlund, "Reducing Health and Safety Risks on Poorly Maintained Rural Roads," in Heavy Vehicle Transport Technology symposium, Melbourne, 2010.

[3] B. Psarianos and K. Apostoleris, "Construction of a Rounded Skew-Superelevation," Current Trends in Civil \& Structural Engineering, pp. ISSN: 2643-6876 DOI: 10.33552/CTCSE.2019.02.000546, 2019.

[4] K. Apostoleris, B. Psarianos, I.-A. Choupas and V. Matragos, "Skew Superelevation Edge Rounding Design Improving Riding Comfort on Freeways," Transportation Research Record, Vols. 2673 (1) 343-357, no. National Academy of Sciences:, p. National Academy of Sciences: Transportation Research Board 2019 Article reuse guidelines: https://journals.sagepub.com/doi/10.1177/036119 8118821680, 2019.

[5] Anadelta Tessera, "http://www.anadelta.com," Anadelta Tessera, 2712 2020. [Online].

[6] K. Apostoleris, B. Psarianos, I.-A. Choupas and V. Matragos, "Skew Superelevation Edge Rounding Design Improving Riding Comfort on Freeways," Vols. 2673 (1) 343-357, no. National Academy of Sciences:, 2019.

[7] P. Sathishkumar, J. Jancirani, D. John and S. Manikandan, "Mathematical modelling and simulation quarter car vehicle suspension," February 2014.

[8] M. Apicella, Ride Model Analysis - The Development of Motorcycle Suspension Damping to Optimise Vehicle Grip Through Vehicle Dynamics Fundamental Model Formulations, Coventry: Coventry University, 2015. 
Contribution of Individual Authors to the Creation of a Scientific Article (Ghostwriting Policy)

The authors confirm contribution to the paper as follows: study conception and design: P. Lemonakis, G. Kaliabetsos, and N. Moisiadis; analysis and interpretation of results: P. Lemonakis, G. Kaliabetsos, N. Moisiadis and N. Eliou; draft manuscript preparation: P. Lemonakis, G. Kaliabetsos, N. Eliou. All authors reviewed the results and approved the final version of the manuscript.

\section{Sources of Funding for Research Presented} in a Scientific Article or Scientific Article Itself

This research study was conducted under the postdoc scholarship supported by the University of Thessaly and exclusively funded by Stavros Niarchos Foundation.

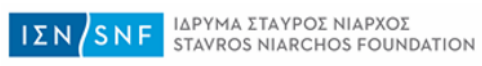

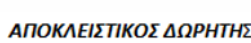

Creative Commons Attribution License 4.0 (Attribution 4.0 International, CC BY 4.0)

This article is published under the terms of the Creative Commons Attribution License 4.0 https://creativecommons.org/licenses/by/4.0/deed.en US 